Ensayo

\title{
La estética como fuente del despertar de las ciencias en Charles Darwin
}

\author{
Aesthetics as the cause for awakening the sciences in Charles Darwin
}

\author{
María Noel Lapoujade* \\ Canelones, Uruguay
}

El punto extremo que alcanzan los conocimientos humanos, en un sentido, sea el que fuere, ofrece siempre inmenso interés, tanto mayor quizás cuanto que nada le separa del reino de la imaginación Charles Darwin (2014/1839, p. 265).

El mundo es admirado antes de ser verificado. El mundo es bello antes de ser verdadero Gaston Bachelard (1943, p.216)

\begin{abstract}
Resumen: En el presente artículo propongo una nueva perspectiva sobre Charles Darwin, necesaria porque los estudios académicos encasillan su pensamiento en un espíritu pura y exclusivamente científico e ignoran las vertientes estéticas y poéticas las cuales afloran a lo largo de sus obras. El tema se desarrolla en la frontera de la Filosofía y la Psicología. La estética funge como articulación de estas dos ramas del conocimiento, a través de las experiencias estéticas en el seno del funcionamiento lógico de la mente de Darwin. El método parte de las premisas de la investigación. Con base en el propósito y en las premisas en las que se fundamenta el artículo, el tema recorre: primero, el Diario del viaje de un naturalista alrededor del mundo (1831-1836), segundo evidencia la presencia del Diario en El origen de las especies por medio de la selección natural (1859). La conclusión ratifica el sentido de los epígrafes, como claves del sentido del paper.
\end{abstract}

Palabras clave: estética, Darwin, ciencias, diario, especies

Abstract: In this article I propose a new perspective on Charles Darwin, needed because academic studies categorize his thinking into a spirit that is purely and exclusively scientific and ignore the aesthetic and poetic aspects which emerge throughout his works. The theme develops within the border of Philosophy and Psychology. Aesthetics works as a hinge between these two branches of knowledge through the aesthetic experiences in the heart of the logical functioning of Darwin's mind. The method emanates from the premises of the research. Based on the purpose and the premises that underlie this article, the theme encompasses: firstly, Journal of Researches into the Natural History and Geology of the Countries Visited during the Voyage of HMS Beagle round the World, under the Command of Capt. Fitz Roy [Diario del viaje de un naturalista alrededor del mundo] (1831-1836), secondly, evidence of the presence of the Journal in On the Origin of Species by Means of Natural Selection [El origen de las especies por medio de la selección natural] (1859). The conclusion confirms the meaning of the headings as key for the meaning of the paper.

Keywords: aesthetics, Darwin, sciences, journal, species

\section{(c) $)$ EY}

Esta obra está bajo una licencia de Creative Commons Reconocimiento 4.0 Internacional 
Cómo citar:

Lapoujade, M. N. (2020). La estética como fuente del despertar de las ciencias en Charles Darwin. Ciencias Psicológicas, 14(2), e-2205. doi: https://doi.org/10.22235/cp.v14i2.2205

Correspondencia: María Noel Lapoujade,e-mail: maría.noel.lapoujade@gmail.com

\section{El título y sus implicaciones}

El título apunta a situar al lector en la pista del desarrollo del tema del artículo, en la frontera de la Filosofía con la Psicología. En este estudio propongo la Estética como articulación de ambas áreas, algunos de sus vasos comunicantes.

Ante todo, pues propongo una nueva mirada sobre Charles Darwin, a quien las obras sobre su pensamiento en general lo encasillan en un espíritu científico a rajatablas, cuyo espíritu asimismo estético y poético se ignoran.

\section{¿Qué entendemos por Estética en la presente investigación?}

Entre las múltiples y complejas relaciones de cada individuo con el medio circundante, llamémosle: el mundo, son importantes las relaciones estéticas con seres, objetos, situaciones o fenómenos, cualesquiera ellos sean. Es lo que llamamos estética espontánea, es decir, no sistemática, no metódica ni filosófica, sino natural, con o sin teorías que la fundamenten. Por relaciones estéticas en este contexto entiendo relaciones de gozo estético, placer o desplacer, sentidos, vividos, maneras de vivir, es decir, experimentar la belleza en cuanto expresión de la vida humana sana, animal, vegetal, natural y, por lo tanto, cósmica. Estas experiencias suelen culminar en afirmaciones en general exclamativas sobre la belleza del ser u objeto en cuestión. Ese impacto es expuesto en juicios de valor por los que se declara la belleza del objeto.

Esta situación se pone de relieve claramente en presencia de lo desconocido, tal como fenómenos naturales, seres, objetos o situaciones. Esta relevancia se constata fundamentalmente porque el conocimiento directo del ser, objeto, fenómeno, situación está ausente, por así decir, no existe conocimiento previo del asunto.

\section{¿Por qué es altamente relevante la lectura minuciosa del Diario del viaje de Charles Darwin alrededor del mundo?}

En particular, respecto de nuestro escrito, el Diario del viaje de Darwin alrededor del mundo, 1831-1836, pone de manifiesto la rica y compleja personalidad de Darwin. El Diario narra el viaje en el cuál navegó y desembarcó en lugares absolutamente desconocidos por el científico, respecto de los cuales las primeras vivencias son estéticas. Finalmente, el Diario es un material de valor insustituible para poner a prueba las premisas que fundamentan mi artículo y quedan absolutamente confirmadas en las palabras de Darwin.

\section{¿En qué consiste el Diario?}

Esta obra que considero debería ser ineludible en la enseñanza en general en cualquier latitud, Darwin registra y narra sus cientos de experiencias de encontrarse ante lo desconocido: geografías, climas, fenómenos naturales, piedras, plantas, animales, seres humanos, con sus costumbres, lenguas, culturas, religiones...

La narración de estos episodios se realiza siempre según una lógica interna espontánea que, considero, es la lógica indeliberada, natural de su subjetividad, la estructura lógica de sus pensamientos integrados en el tejido de la psique. 


\section{Premisas de esta investigación}

Primera. La "corriente" (W. James) de la mente, psique, tiene su fuente que la impulsa a irrumpir en sus más diversos procesos. De acuerdo con Gaston Bachelard sostengo la siguiente tesis, a la base de mi perspectiva filosófica: la vivencia estética de raíz imaginaria del mundo circundante, tanto de lo desconocido, como de lo conocido es la fuerza que impulsa el despertar de los conocimientos de todo orden, entre otros, los filosóficos, las ciencias y las artes, los mitos y las religiones (Lapoujade,1988; 2008; 2011; 2014/1839; 2017a; 2017b).

Segunda. La psique tiene sus lógicas. Sin entrar en la problemática implícita, afirmo que la "psicología" de cada uno, la "mente", "espíritu" o "subjetividad" de la especie humana, la que defino Homo imaginans funciona asumiendo, poniendo en juego, diversas lógicas, en otras palabras, las lógicas le son inherentes (Lapoujade, 1988).

Tercera. Surge de la relación de las dos anteriores. Los procesos epistémicos brotan en el seno de los procesos estéticos, es decir, los conocimientos emergen en el tejido de las vivencias estéticas de "lo real", según sus propias lógicas internas, así como, lógicas de vigilia, lógicas oníricas, "lógicas" de la ensoñación, etc. [Homenaje a los 70 años de vida de María Noel Lapoujade, Priani Saisó (Coord.),2018].

\section{Objetivos}

Mi propósito es poner en acción estas premisas. Mi argumentación es la mostración, es decir, mostrar, poner en evidencia la viabilidad y operatividad de las premisas.

\section{Método}

El método recorre una obra fuente: Diario de viaje de un naturalista alrededor del mundo de Charles Darwin. Realizo el recorrido con base en un método consistente en la extracción de pasajes relevantes, que permiten comprobar la exactitud de las premisas en las palabras directas de un espíritu indudablemente científico. Se trata de pasajes que reflejan su actitud ante el mundo, una manera de experimentar la realidad que se repite cientos de veces a lo largo de la obra.

\section{Esquema}

El artículo se desarrolla así: 1. Introducción acerca del viaje de C. Darwin.; 2. Análisis del Diario; 3. Presencia del Diario en El origen de las especies; 4. Conclusión.

\section{Capítulo 1. El viaje}

El leit motiv de este paper el Diario de viaje de Charles Darwin alrededor del mundo como naturalista en el Beagle al mando del capitán Robert Fitz-Roy es una obra documental de profundos alcances. En la alternancia de travesías y escalas el viaje duró casi 5 años, de 1831 a 1836. Largas travesías en alta mar, y travesías más cortas bordeando costas de América del Sur, con el fin de trazar mapas más precisos, tenían a Darwin confinado en un camarote compartido con el capitán Fitz Roy durante una convivencia de 5 años en una recíproca experiencia de falta de libertad. El Diario es un documento invaluable, porque conserva los registros de su espíritu, de su personalidad y de sus futuras teorías, que iban a cambiar las concepciones del mundo y de la vida con nuevas alternativas.

El Diario es una lente que permite observar los procesos y transmutaciones de su espíritu. Más aún, este documento es un tesoro que muestra los gérmenes de su futura Teoría de la Evolución de las Especies, en su incipiente emergencia. 
En lo que concierne a mi objetivo el Diario es el ojo que me permite registrar la lógica del espíritu de Darwin. Ello arroja resultados sorprendentes respecto de mis propias perspectivas filosóficas que resultan confirmadas a lo largo de los cientos de experiencias y situaciones vividas por nuestro personaje.

\section{Capítulo 2. Análisis del Diario}

\subsection{Naturaleza y paisaje}

En sentido estricto, entiendo por naturaleza el conjunto de todo lo que constituye el planeta tierra sin intervención humana. A partir de allí, todos los usos de la palabra, por extensión.

Defino el paisaje en general como la naturaleza pasada por la criba de una subjetividad humana. En particular llamo paisaje la naturaleza observada por un ojo que la mira estéticamente.

La mirada estética de cualquier índole es el acto de un ojo contemplativo. Lejos de oponerse a la acción, la contemplación es una forma sutil pero potente de acción. La quietud exterior del que mira hace posible que en la subjetividad se viva una intensa eclosión de imágenes de sensaciones, recuerdos, deseos, ideales, proyectos, ansias, críticas, ideas (Lapoujade, 2010).

Un paisaje desconocido impacta en el espíritu del individuo que allí se encuentra, y produce unos efectos, diferentes resonancias en cualidades e intensidades.

La contemplación estética aviva la llama del espíritu, porque enciende la imaginación. Si el espíritu es artista, entonces nace la obra, si el espíritu es científico, detona las hipótesis, teorías, etc. Las respuestas artísticas o científicas ponen de manifiesto las repercusiones del paisaje en el espíritu (Bachelard, 1994).

Ante diversos paisajes nuevos para él, Darwin da cuenta de múltiples resonancias, algunas reiteradas en su Diario. Entre otras encuentra paisajes: "desolados", "pintorescos", "lujuriosos", en ocasiones se siente "sorprendido por las ondulaciones", o bien "paisajes extremadamente ininteresantes", paisajes "inhospitalarios", con "climas detestables", "terribles". Ciertos paisajes inspiran a Darwin poético: "Paisajes adornados con un aire de perfecta elegancia el escenario, si se me permite la expresión, es armonioso".

\subsection{En el umbral de la Estética}

La frontera de las resonancias estéticas del paisaje en su espíritu, en su ánimo, con el surgimiento de relaciones estéticas con el mismo, es un límite sutil. Es un pliegue diferente, un paso más, que consiste en no sólo dar cuenta de, registrar, mostrar los efectos del paisaje en su ánimo sino además establecer, construir cierta relación estética con el mismo. Casi imperceptiblemente hemos pasado sobre un límite tenue, ya estamos en el ámbito de la estética espontánea. Es decir, relaciones estéticas, experiencias y vivencias que no se insertan en una filosofía estética sistemática y metódica.

En cuanto a su estilo, Darwin aúna la objetividad más descarnada del estilo científico puro, en que el investigador deja a un lado sus reacciones subjetivas, con una refinada y bella prosa poética, en la que deja aflorar y muestra las profundas resonancias de los animales, plantas, paisajes, naturaleza en su espíritu, son los profundos registros estéticos de nuestro naturalista.

Un pasaje en que su ojo estético prevalece, Darwin invoca el deleite del lector cuando comenta:

Bahia or San Salvador Brazil, Feb. 29 th.-The day has past delightfully. Delight itself, however, is a weak term to express the feelings of a naturalist who, for the first time, has wandered by himself in a Brazilian forest. The elegance of the grasses, the novelty of the parasitical plants, the beauty of the flowers, the glossy green of the foliage, but above all 
the general luxuriance of the vegetation, filled me with admiration. A most paradoxical mixture of sound and silence pervades the shady parts of the wood. The noise from the insects is so loud, that it may be heard even in a vessel anchored several hundred yards from the shore; yet within the recesses of the forest a universal silence appears to reign. To a person fond of natural history, such a day as this brings with it a deeper pleasure than he can ever hope to experience again. After wandering about for some hours, I returned to the landing-place; but, before reaching it, I was overtaken by a tropical storm. I tried to find shelter under a tree, which was so thick that it would never have been penetrated by common English rain; but here, in a couple of minutes, a little torrent flowed down the trunk. It is to this violence of the rain that we must attribute the verdure at the bottom of the thickest woods: if the showers were like those of a colder clime, the greater part would be absorbed or evaporated before it reached the ground. I will not at present attempt to describe the gaudy scenery of this noble bay, because, in our homeward voyage, we called here a second time, and I shall then have occasion to remark on it $(2014 / 1839, \mathrm{p} .11-12)$

\subsection{Situados en el ámbito de la estética}

1. El campo de la estética tiene diversos, amplios y lejanos alcances. No se debe confundir con las Teorías del Arte, Historia del Arte o de las Artes. Ellas se incluyen en el campo de la estética, pero Estética abarca todo tipo de relaciones estéticas con todo tipo de objeto, real o posible, presente, pasado, futuro o utópico, natural, social, artificial.

Es posible simplificar la compleja problemática de este tema, si establecemos, con la Estética de I. Kant, dos tipos de juicios o aseveraciones estéticos: el que juzga sobre lo bello, el que juzga de lo sublime. Así se describen dos experiencias estéticas radicales. La experiencia de lo bello, la experiencia de lo sublime.

Es muy sorprendente la claridad con la que el científico Darwin plasma en juicios exactos esas radicales experiencias estéticas, como si estuviera aplicando al pie de la letra la Estética kantiana.

Según Kant, en síntesis, el juicio de lo bello, cuya fórmula es [Esto es bello] es el resultado final por el que el sujeto comunica su intensa vivencia estética de goce, placer estético, "Lust", que el sujeto siente ante la representación, esto es, la imagen mental de un "objeto x".

El goce surge al experimentar la armonía en las acciones de la imaginación (productora de imágenes) y el entendimiento (función emisora de conceptos).

\section{4 ¿En qué consiste esa armonía?}

Consiste en que el sujeto imagina libremente lo que se le ocurra, sin constricciones, ni normas. Por su parte el entendimiento puede pensar en conceptos igualmente libres. Es lo que Kant llama "libre juego de la imaginación con el entendimiento". Dejar los procesos mentales en libertad, sin prohibiciones, censuras, exigencias de verdad, de coherencia lógica evidentemente es muy placentero, es la experiencia de un goce estético o placer estético fundamental.

En cuanto al juicio de lo sublime [Esto es sublime] es el resultado final en el cual el sujeto busca comunicar el goce, placer, "Lust" que experimenta ante la imagen de una naturaleza extrema, de un mar, un bosque, una montaña, unos inmensos "mares de piedra", que le inspiran sensaciones de una naturaleza cuya inmensidad lo desborda, ya sea por la intensidad, la cantidad o por la intensidad de la situación. En última instancia, puede también tratarse de algún fenómeno natural extremo, anormal, de una naturaleza desbordada, silvestre, que Kant denomina "salvaje", porque está fuera de las leyes naturales, tales como tormentas u otros: ciclones, erupciones volcánicas, temblores, siempre que pueda presenciarlos sin verse arrastrado por ellos.

En estas situaciones la imaginación no puede producir imágenes, configuraciones, pues 
ellas son siempre limitadas. Por su parte la razón puede proponer ideas ilimitadas como la idea de totalidad, a la que siempre nos acercamos sin poderla aprehender.

En este caso hay una desarmonía entre la imaginación y la razón. Paradójicamente el sujeto siente un placer, un goce estético en la vivencia de esa desarmonía.

En cuanto a la vivencia estética, la resonancia de las imágenes de un objeto que provoca el que se le juzgue bello es muy diferente a la resonancia de las imágenes que la naturaleza sin ley, silvestre, salvaje provoca en el espectador.

Lo bello implica una serena contemplación, un goce apacible ante los seres que habitan la naturaleza en su normalidad, plantas, animales, piedras, montañas, ríos, cielos.

Lo sublime expresa un sentimiento de goce, pero con temor y respeto por la magnificencia de una naturaleza que no se deja legislar, una naturaleza en estado salvaje, ante la cual el espectador se siente pequeño, impotente, a merced de esos fenómenos infinitamente grandes y poderosos (Kant, 1968).

La majestuosidad de estos fenómenos suscita asombro con temor, y respeto por esa naturaleza "todopoderosa". El sentimiento de respeto enlaza esta experiencia estética con la experiencia moral, pues la ley moral inspira respeto. Precisamente el respeto es lo que determina a que la ley moral se asuma como ley. Así se unen las vivencias estéticas con las éticas.

Darwin (2014/1839) describe así la naturaleza sublime:

If the eye was turned from the world of foliage above, to the ground beneath, it was attracted by the extreme elegance of the leaves of the ferns and mimosæ. The latter, in some parts, covered the surface with a brushwood only a few inches high. In walking across these thick beds of mimosæ, a broad track was marked by the change of shade, produced by the drooping of their sensitive petioles. It is easy to specify the individual objects of admiration in these grand scenes; but it is not possible to give an adequate idea of the higher feelings of wonder, astonishment, and devotion, which fill and elevate the mind (p.26).

En otro pasaje Darwin esteta manifiesta su sentimiento de lo sublime en estas palabras:

We obtained a wide view over the surrounding country: To the north a swampy moorland extended, but to the south we had a scene of savage magnificence, well becoming Tierra del Fuego. There was a degree of mysterious grandeur in mountain behind mountain, with the deep intervening valleys, all covered by one thick, dusky mass of forest.But it would be difficult to imagine a scene where he seemed to have fewer claims or less authority. The inanimate works of nature - rock, ice, snow, wind, and water, all warring with each other, yet combined against man - here reigned in absolute sovereignty. (2014/1839, p.197)

Evoco un pasaje en el cual se hace patente el temblor abisal de la experiencia estética en Darwin (2014/1839):

When we reached the crest and looked backwards, a glorious view was presented. The atmosphere resplendently clear; the sky an intense blue; the profound valleys; the wild broken forms: the heaps of ruins, piled up during the lapse of ages; the bright-coloured rocks, contrasted with the quiet mountains of snow, all these together produced a scene no one could have imagined. Neither plant nor bird, excepting a few condors wheeling around the higher pinnacles, distracted my attention from the inanimate mass. I felt glad that I was alone: it was like watching a thunderstorm, or hearing in full orchestra a chorus of the Messiah. (p.301-302)

La experiencia estética de Darwin sube un peldaño más. La vivencia estética radical es una experiencia místico-estética de fusión, de anulación del yo individual para alcanzar lo bello y lo sublime. Alcanzado este grado el goce estético provoca la felicidad.

Es una vivencia ético-estético-mística de la felicidad. Aquello que Goethe vivió en su Fausto: "minuto detente, eres tan bello", es una vivencia de la totalidad y de la eternidad del 
instante.

2. Los matices de la estética en Darwin son de una riqueza sorprendente. El naturalista despliega todas sus ciencias a partir de una previa, radical experiencia estética. El tránsito va de la estética a las ciencias y a la epistemología. Más aún, el sendero lleva a la etnología, así como a su interpretación de los mitos y las religiones.

\subsection{De la estética a las ciencias}

A lo largo del Diario abundan los pasajes en que Darwin transita con agilidad de la estética a las ciencias que constituyen la médula de sus preocupaciones.

Es notable el conjunto de ciencias naturales convocadas en su obra. Es preciso señalar que Darwin naturalista incluye investigaciones en ciencias aún no identificadas como tales en su tiempo, las cuáles constituyen hoy sendas ramas de las ciencias naturales.

El tránsito de la vivencia estética del paisaje a la geografía física, y a la geología fluye sin tropiezos. Las descripciones geológicas eruditas y minuciosas aparecen con intervalos de pocas páginas. Pero el geólogo observa con detenimiento en cada hábitat su flora y su fauna: terrestre, acuática y aérea. Así, trabaja Darwin el botánico y el zoólogo, sin descuidar su faceta de consumado entomólogo. Además, estudia el comportamiento, las costumbres, de los animales en su medio, su Umwelt (Uexküll) su mundo circundante. Así, la etología está omnipresente. Entre sus andanzas científicas Darwin ejercita su pasión por la caza.

El hallazgo, estudio y recopilación de fósiles merece un capítulo aparte. El estudio de los fósiles en su interdependencia con las etapas geológicas, integrados con los estudios de la flora y fauna vivientes en sus geografías físicas, van construyendo la trama de la futura Teoría de la Evolución.

Asistimos a un hecho rara vez constatado: la gestación en el espíritu de su creador, de una de las grandes teorías que cambian irreversiblemente el curso histórico de las ciencias, la antropología, la filosofía. El Viaje ha sido para Darwin la más alta escuela de sabiduría.

\section{Capítulo 3. Presencia del Diario en El Origen de las Especies}

El reloj de la naturaleza no sólo testimonia las etapas de su historia, sino que mueven al científico teórico a reflexiones profundas y lo conducen a plantearse preguntas, cuyas respuestas primarias contienen ya visibles los gérmenes de la Teoría de la Evolución de las especies titulada: El origen de las especies, Por medio de la selección natural (1859).

En el marco del presente estudio bastan unas referencias de enlace entre las dos obras, pero no un análisis minucioso del Origen de las especies.

La obra se abre con una declaración que confirma la pertinencia del presente estudio en cuanto a la presencia en germen de la Teoría de la Evolución en el matraz del Diario del viaje que venimos de analizar. Dice Darwin (2019/1859):

Cuando me encontraba como naturalista en el Beagle, buque de la marina real, me llamaron mucho la atención ciertos hechos que se presentan en la distribución geográfica de los seres orgánicos que viven en América del Sur y en las relaciones geológicas entre los habitantes actuales y los antiguos de aquel continente. (p. 63)

Esta obra, continúa el naturalista, es "un resumen".

\section{1 ¿Qué entiende el autor por especie?}

La noción que Darwin (2019/1859), propone no es más que un acuerdo semántico. Al respecto afirma:

Considero la palabra "especie" como la que se aplica arbitrariamente, por razón de conveniencia, a un grupo de individuos muy semejantes y que no difiere en esencia de la palabra "variedad" que se aplica a formas menos precisas y más fluctuantes. (p.122)

A su vez la noción de variación, supone la premisa problemática de "la comunidad de 
origen" (Darwin, 2019/1859, p.109).

Una variación si es útil para la sobrevivencia de la especie, favorable a la vida de esa especie, entonces se conserva. Por el contrario, si es perjudicial, se destruye. Las variaciones se van acumulando, pero los pequeños cambios son imperceptibles, aunque continuos y progresivos (Darwin, 2019/1859).

Las mutaciones de una especie, resultantes de la selección natural que implica la lucha por la vida, transcurren con "extrema lentitud".

Se van produciendo en los largos tiempos geológicos, de manera continua pues, sostiene Darwin (2019/1859, p. 287) con la tradición, "la naturaleza no hace saltos".

Este hecho es lo que Darwin llama "selección natural", y que Herbert Spencer, llama supervivencia de los más aptos, expresión más exacta según nuestro autor.

Ambas nociones presuponen lo que Darwin llama "lucha por la existencia", expresión que emplea, como él mismo aclara en sentido amplio y metafórico. Concluye: "El vigoroso, el sano, el feliz, sobrevive y se multiplica" (Darwin, 2019/1859, p.150).

Por mi parte considero que todo ello supone lo que Baruch Spinoza llamó conato, desde el punto de vista filosófico y salvando las diferencias, entendido como el impulso para persistir en su ser (Spinoza, 1965).

En general el conato significa el impulso a la vida, a la sobrevivencia, a conservarse vivo.

En otros de sus pasajes Darwin el esteta sensible reflexiona de manera explícita y profunda sobre el tema estético por esencia: la Belleza.

En primer término, menciona y refuta la Teoría de los naturalistas que sostienen que muchas conformaciones naturales fueron creadas con una finalidad estética, para deleite de la belleza.

En segundo término, Darwin (2019/1859), nuevamente muy afín con la estética kantiana afirma:

En cuanto a la opinión que los seres orgánicos han sido creados para el deleite humano, opinión que, como se ha dicho, desmonta toda mi teoría, señalaré en primer lugar que, como es evidente, el sentido de la belleza depende de la naturaleza de la mente que la juzga, con independencia de toda cualidad real en el objeto admirado. (p. 294)

Sin embargo, es posible encontrar bellezas naturales, por ejemplo, en las conchas marinas, en las flores, en los frutos, en las aves y mamíferos, así como muchos peces y reptiles y las mariposas de vistosos colores acerca de lo cual recojo un pasaje que en sí mismo es una joya de sabiduría:

Se han vuelto hermosos por su propio deseo de hermosura; pero esto se ha efectuado por obra de la selección sexual, es decir porque los machos más hermosos han sido preferidos continuamente por las hembras, y no para deleite humano. Lo mismo ocurre con el canto de las aves. De ello se podría deducir que un gusto casi igual por los colores hermosos y los sonidos musicales se extiende a una gran parte del mundo animal. (Darwin, 2019/1859, p.295).

Darwin (2019/1859, p.296) manifiesta que: "Es un problema oscurísimo cómo el sentimiento de belleza en su forma más simple, esto es, el sentir cierto tipo de placer ante ciertos colores, formas y sonidos, se desarrolló por vez primera en la mente humana y en los animales superiores".

La sobrevivencia de las especies mediante sus variaciones según el científico-esteta "Estas modificaciones aumentarán la hermosa y armónica diversidad de la naturaleza" (Darwin, 2019/1859, p. 253).

Para concluir, pues en algún lugar hay que poner un punto, cerramos el círculo de nuestra tesis central: el indiscutible espíritu científico de Darwin, el científico múltiple y sabio, muestra su veta estético poética que pocas veces es recuperada por los especialistas ortodoxos de las ciencias puras. 
El texto completo confirma el epígrafe de Bachelard.

Por mi parte considero que ahí se encuentran las pruebas de la justeza de mis tesis y propuestas filosóficas, de que vamos por buen camino. Es lo que sostengo en mi perspectiva filosófica basada en una concepción de la especie como Homo Imaginans, en quien el detonante de su carácter de especie humana es el thauma estético primordial.

Para terminar, leemos la última frase de esta obra monumental: "Mientras este planeta ha seguido girando según la constante ley de la gravitación, se han desarrollado y se están desarrollando, a partir de un principio tan sencillo, infinidad de las más bellas y maravillosas formas" (Darwin, 2019/1859, p.677).

En fin, estas obras, son un Tesaurus de la ciencia universal, y El origen de las especies se cierra con broche de oro: un pasaje poético estético, para confirmar una y otra vez, nuestra propuesta para una nueva hermenéutica de este genio de la humanidad.

\section{Referencias}

Bachelard, G. (1943). L'air et les songes. Paris: J. Corti.

Bachelard, G. (1994). La poétique de l'espace. Paris: P.U.F.

Darwin, C.R. (2014/1839). Viaje de un naturalista alrededor del mundo. Madrid: Miraguano.

Darwin, C.R. (2019/1859). El origen de las especies. Barcelona: Penguin Random House Grupo Editorial.

Kant, I. (1968). Crítica de la Facultad de Juzgar. Frankfurt: Suhrkamp Verlag.

Lapoujade, M.N. (1988). Filosofía de la imaginación. México D.F.: Siglo XXI.

Lapoujade, M.N. (2008). La imaginación estética en la mirada de Vermeer. México D.F.: Herder.

Lapoujade, M.N. (2010). Itinerario hacia la comprensión de lo sublime y lo siniestro en el paisaje de Siqueiros, en Siqueiros paisajista. México D.F.: Museo de Arte Carrillo Gil (MACG).

Lapoujade, M.N. (2011). Diálogo con G. Bachelard acerca de la poética. México D.F.: Universidad Nacional Autónoma de México, UNAM.

Lapoujade, M.N. (2014). Homo Imaginans, Vol I. México D.F.: Benemérita Universidad Autónoma de Puebla, BUAP.

Lapoujade, M.N. (2017a). L'imagination esthétique. Le regard de Vermeer. Paris: ÉMÉ Éditions-L'Harmattan, Lovaina la Nueva

Lapoujade, M.N. (2017b). Homo Imaginans, Vol II. México D.F.: Benemérita Universidad Autónoma de Puebla, BUAP. Recuperado de: https://lafuente.buap.mx Homo Imaginans. Vol II

Priani Saisó, E. (Coord.) (2018). Homenaje a los 70 años de vida de María Noel Lapoujade.

México D.F.: UNAM. Recuperado de: http//ru.ffyl.unam.mx/handle/10391/6669

Spinoza, B. (2017). Oeuvres de Spinoza, Ethique, Vol III. Paris: GF-Flammarion.

\footnotetext{
* María Noel Lapoujade (Montevideo, 1942). Doctora en Filosofía por la Universidad de París (Francia) y Doctora en Filosofía por la UNAM (México). Posgrado en la Universidad de Heidelberg (Alemania). Dos posdoctorados en la Universidad de París. Profesora de tiempo completo en la FFYL-UANM (1975-2012). Su obra erige una filosofía original: Filosofía de la imaginación, las imágenes y los imaginarios, desde una perspectiva antropológica-estético-ética-epistemológica, con base en su concepción del Homo Imaginans. Premios en España, México, Uruguay. Incluida en el Biographical Dictionary of Twentieth-Century Philosophers (Londres-New York), en Identidad, Integración y Creación cultural en América Latina (UNESCO) y en la Enciclopedia electrónica de la filosofía mexicana (México, 2018). Artículos publicados en Brasil, Argentina, Colombia, Venezuela, El Salvador, Costa Rica, Estados Unidos, Francia, Inglaterra, Alemania, Dinamarca, Italia, Bulgaria y Rumania. Libros: Filosofía de la Imaginación (México, 1988); Bacon y Descartes. De la coincidencia de los opuestos (México, 2002); La imaginación estética en la mirada de Vermeer (México, 2007); Diálogo con Gaston Bachelard acerca de la Poética (México, 2011); L'imagination esthétique. Le regard de Vermeer (Bélgica-Francia, 2017); Homo Imaginans, Ensayos completos en cuatro volúmenes (vol. I, 2014, y vol. II, 2017, México). Compiladora de Espacios Imaginarios (México, 1999); Imagen, Signo y símbolo (México, 2000); Tiempos imaginarios: ritmos y ucronías (México, 2002). Libro colectivo: Homenaje a María Noel Lapoujade, 70 años de vida, 2012 (México, 2018).
} 